\title{
Gasoline price effects on traffic safety in urban and rural areas: Evidence from Minnesota, 1998-2007
}

\author{
Guangqing Chi ${ }^{\mathrm{a}, *}$, Mohammed A. Quddus ${ }^{\mathrm{b}, 1}$, Arthur Huang ${ }^{\mathrm{c}, 2}$, David Levinson ${ }^{\mathrm{c}, 3}$ \\ ${ }^{a}$ Department of Sociology and Social Science Research Center, Mississippi State University, PO Box C, Mississippi State, MS 39762, United States \\ ${ }^{\mathrm{b}}$ Department of Civil and Building Engineering, Loughborough University, Leicestershire LE11 3TU, United Kingdom \\ ${ }^{\mathrm{c}}$ Department of Civil Engineering, University of Minnesota, 500 Pillsbury Drive SE, Minneapolis, MN 55455, United States
}

\section{A R T I C L E I N F O}

Article history:

Received 24 February 2012

Received in revised form 3 May 2013

Accepted 24 May 2013

\section{Keywords:}

Gasoline prices

Traffic safety

Urban-rural difference

Traffic crashes

\begin{abstract}
A B S T R A C T
A large literature base has found that economic factors have important effects on traffic crashes. A small but growing branch of literature also examines the role of gasoline prices in the occurrence of traffic crashes. However, no studies have investigated the possible difference of these effects between urban and rural areas. In this study, we used the monthly traffic crash data from 1998 to 2007 at the county level in Minnesota to investigate the possibly different effects gasoline prices may have on traffic crashes per million vehicle miles traveled in urban versus rural areas. The results indicate that gasoline price effects on total crashes, property-damage-only crashes, and injury crashes are stronger in rural areas than in urban areas. Gasoline prices also significantly affect fatal crashes in both urban and rural areas; however, the difference is not significant. The results concerning the differences between urban and rural areas have important policy implications for traffic safety planners and decision makers.
\end{abstract}

(c) 2013 Elsevier Ltd. All rights reserved.

\section{Introduction}

A large body of literature has found that economic factors have important effects on traffic safety (see Traynor, 2008, for a review of the literature). An increasing, but still limited, number of studies have examined the possible role of gasoline prices in affecting traffic safety with a general consensus that rising gasoline prices reduces occurrence of traffic crashes (e.g., Chi et al., 2010). These studies analyzed the association of gasoline prices to total traffic crashes, fatal crashes, drunk-driving crashes, and motorcycle crashes, as well as the demographic variations of the association. However, no studies have examined the possible variation of the association of gasoline prices to traffic crashes in urban versus rural areas caused by differences in commuting behavior characteristics, transportation infrastructure, and socioeconomic contexts (Levinson and $\mathrm{Wu}, 2005$ ).

Gasoline price effects on traffic crashes in urban versus rural areas may differ in two possible directions-they may be stronger in urban areas or stronger in rural areas. On the one hand, gasoline prices may have stronger effects on reducing crashes in urban areas than in rural areas because urban areas offer relatively better

\footnotetext{
* Corresponding author. Tel.: +1 662325 7872; fax: +1 6623257966 .

E-mail addresses: gchi@ssrc.msstate.edu (G. Chi), m.a.quddus@lboro.ac.uk (M.A. Quddus), huang284@umn.edu (A. Huang), dlevinson@umn.edu (D. Levinson).

1 Tel.: +44 150922 8545; fax: +44 1509223981

2 Tel.: +1 612626 0024; fax: +1612626 7750

3 Tel.: +1 612625 6354; fax: +16126267750.
}

transportation infrastructure so that urban commuters could switch from personal vehicles to public transportation, car pool, biking, and walking in response to rising gasoline prices (Currie and Phung, 2008). In most rural areas, however, public transportation does not exist so that, regardless of gasoline prices, people depend on their own cars. Therefore, we would expect that gasoline price effects on reducing traffic crashes are stronger in urban areas than in rural areas.

On the other hand, gasoline prices may have stronger effects on reducing crashes in rural areas than in urban areas because gasoline is one type of consumer goods (Goodwin et al., 2004). The purchase power of gasoline largely relies on the income level: individuals with higher incomes are more resilient to gasoline price rises while those with lower incomes are more vulnerable to higher gasoline price rises. Generally, urban commuters command a relatively higher level of income than rural commuters do. Consequently, identical or similar gasoline price increases would matter less to urban commuters than to rural commuters. Therefore, we would expect gasoline price effects on reducing traffic crashes to be stronger in rural areas than in urban areas.

While both explanations about gasoline price effects on reducing traffic crashes in urban versus rural areas seem reasonable, they are also contradictory. In this study, we use monthly traffic crash data from 1998 to 2007 at the county level in Minnesota to investigate the possibly different effects of gasoline prices on total crashes, property-damage-only (PDO) crashes, injury crashes, and fatal crashes in urban versus rural areas. This article is organized into five additional sections. The next section provides an 
extensive summary of existing studies on the relationship between gasoline prices and traffic safety. The two following sections introduce the data related to monthly traffic crashes in Minnesota from 1998 to 2007 and address the methods that directed our analyses. The results section reports our findings. Finally, the present study concludes with a summary and discussion of our results.

\section{Prior research}

A large body of literature has found an association between economic factors and traffic safety (e.g., Kopits and Cropper, 2005; Scuffham, 2003; Sivak and Schoettle, 2010; Traynor, 2008, 2009). These studies generally found that, in a stable or prosperous economy, people drive more and drive more aggressively, leading to a decreased level of traffic safety; in contrast, in an economic downturn, people drive less and drive more carefully, leading to improved traffic safety. In addition, economic conditions could change vehicle fleet composition and lead people to relocate over time, which would in turn affect traffic safety as well (Chi et al., 2010). Among economic factors linked to traffic safety, income and employment have been studied the most. Lower income forces people to drive less by reducing trip frequency and distance, switching from personal vehicles to public transportation, converting single-purpose trips to multi-purpose trips, and reducing vacation trips in order to save on gasoline expenditures. Higher unemployment rates reduce work-related trips. However, the possible linkage of gasoline prices to traffic safety is largely neglected in existing literature.

The relationship between gasoline price changes and traffic safety has been studied in a limited body of literature. Our literature search resulted in eleven journal articles that are specifically focused on gasoline prices (or taxes) and traffic crashes. These studies produced understanding on the relationship between gasoline prices and traffic crashes from six perspectives: gasoline price effects on total traffic crashes, gasoline price effects on fatal crashes, gasoline price effects on drunk-driving crashes, gasoline price effects on motorcycle crashes, the effects by demographic characteristics, and the short-term or long-term effects (Table 1).

First, the five most recent studies examined gasoline price effects on total traffic crashes. Using Mississippi monthly traffic crash data from April 2004 to December 2010, Chi et al. (2010, 2011, 2013) examined the relationship of gasoline prices with traffic crashes. Their findings indicate that rising gasoline prices lead to reduction in both the frequency and rate of traffic crashes. They argued that traffic crash frequency is reduced because drivers may reduce travel frequency and distance for non-work trips as well as switch from personal vehicles to carpool or public transportation in response to gasoline price increases. They also argued that the rate of traffic crashes was reduced because drivers may improve their driving behaviors by reducing immediate braking or speeding in response to gasoline price increases. Similarly, Huang and Levinson (2010) found that higher gasoline prices reduced traffic levels and reduced traffic diminished the number of total crashes from 2001 to 2007 in Minnesota. In addition, Chi et al. (2012) found that higher gasoline prices reduced traffic crashes per capita from 1999 to 2009 in Alabama.

Second, early studies are focused on fatal crashes. All these studies used the Fatality Analysis Reporting System data (with one exception, which used data from the Centers for Disease Control and Prevention) to study gasoline price effects on the incidence of fatal crashes in the United States over a relatively long time period. For example, the study by Wilson et al. (2009) was conducted

Table 1

Prior studies on gasoline prices and traffic safety.

\begin{tabular}{|c|c|c|c|c|c|c|}
\hline Study & Study area & $\begin{array}{l}\text { Data set/ } \\
\text { source }\end{array}$ & $\begin{array}{l}\text { Time } \\
\text { period }\end{array}$ & Crash types & $\begin{array}{l}\text { Demographic } \\
\text { groups }\end{array}$ & $\begin{array}{l}\text { Short- or } \\
\text { long- } \\
\text { term effects }\end{array}$ \\
\hline Leigh and Wilkinson (1991) & US & FARS $^{\mathrm{a}}$ & 1976-1980 & Fatal crashes & None & Short-term \\
\hline $\begin{array}{l}\text { Grabowski and Morrisey } \\
\quad(2004)\end{array}$ & US & FARS $^{\mathrm{a}}$ & $1983-2000$ & Fatal crashes & Variation by age & Both \\
\hline $\begin{array}{l}\text { Grabowski and Morrisey } \\
\quad(2006)\end{array}$ & US & FARS $^{\mathrm{a}}$ & $1982-2000$ & Fatal crashes & None & Short-term \\
\hline Leigh and Geraghty (2008) & US & $\mathrm{CDC}^{\mathrm{b}}$ & 1999-2003 & Fatal crashes & None & Short-term \\
\hline Wilson et al. (2009) & US & FARS $^{\mathrm{a}}$ & 1990-2007 & Motorcycle fatal crashes and vehicle fatal crashes & None & Short-term \\
\hline Hyatt et al. (2009) & US & $\begin{array}{l}\text { NASS GES }{ }^{\mathrm{c}} \text { and } \\
\text { FARS }^{\mathrm{a}}\end{array}$ & $1992-2007$ & $\begin{array}{l}\text { Motorcycle fatal crashes, motorcycle injury } \\
\text { crashes, } \\
\text { vehicle fatal crashes, and vehicle injury } \\
\text { crashes }\end{array}$ & $\begin{array}{l}\text { Variation by age } \\
\text { and gender }\end{array}$ & Short-term \\
\hline $\begin{array}{l}\text { Huang and Levinson } \\
\text { (2010) }\end{array}$ & Minnesota & $\mathrm{MnOTS}^{\mathrm{d}}$ & 2001-2007 & Total traffic crashes, and fatal crashes & None & Short-term \\
\hline Chi et al. (2010) & Mississippi & $\mathrm{MHP}^{\mathrm{e}}$ & $\begin{array}{l}04 / 2004-12 / \\
2008\end{array}$ & Total traffic crashes & $\begin{array}{l}\text { Variation by } \\
\text { age, } \\
\text { gender, and race }\end{array}$ & Both \\
\hline Chi et al. (2011) & Mississippi & MHPe & $\begin{array}{l}04 / 2004-12 / \\
2008\end{array}$ & $\begin{array}{l}\text { Total traffic crashes, drunk-driving } \\
\text { crashes, fatal crashes, injury crashes, } \\
\text { and property-damage-only } \\
\text { crashes }\end{array}$ & $\begin{array}{l}\text { Variation by } \\
\text { age, } \\
\text { gender, and race }\end{array}$ & Short-term \\
\hline Chi et al. (2012) & Alabama & ALCARE $^{\mathrm{f}}$ & 1999-2009 & Total traffic crashes & $\begin{array}{l}\text { Variation by } \\
\text { age, } \\
\text { gender, and race }\end{array}$ & Both \\
\hline Chi et al. (2013) & Mississippi & $\mathrm{MHP}^{\mathrm{e}}$ & $\begin{array}{l}04 / 2004-12 / \\
2008\end{array}$ & Total traffic crashes, and fatal crashes & $\begin{array}{l}\text { Variation by } \\
\text { age, } \\
\text { gender, and race }\end{array}$ & Both \\
\hline
\end{tabular}

\footnotetext{
${ }^{a}$ FARS = Fatality Analysis Reporting System.

b $\mathrm{CDC}=$ the Centers for Disease Control and Prevention.

c NASS GES = the National Automotive Sampling System General Estimates System.

d MnOTS = Minnesota Office of Traffic Safety.

e $\mathrm{MHP}=$ Mississippi Highway Patrol.

f ALCARE = the Alabama Critical Analysis Reporting Environment system.

${ }^{g}$ Refers to whether a study considered or found short-term effect, long-term effect, or both.
} 
Table 2

Descriptive statistics of the variables.

\begin{tabular}{|c|c|c|c|c|c|c|c|}
\hline & $N$ & Mean & Standard deviation & Minimum & Maximum & Time-variant & Space-variant \\
\hline Total crashes & 10,440 & 85.600 & 256.402 & 0 & 4003 & Yes & Yes \\
\hline Property-damage-only crashes & 10,440 & 58.547 & 181.830 & 0 & 3113 & Yes & Yes \\
\hline Injury crashes & 10,440 & 26.549 & 75.527 & 0 & 887 & Yes & Yes \\
\hline Fatal crashes & 10,440 & 0.503 & 0.924 & 0 & 10 & Yes & Yes \\
\hline Gasoline prices (in January 2008 dollars) & 120 & 1.515 & 0.510 & 0.762 & 2.758 & Yes & No \\
\hline Monthly VMT (million) & 10,440 & 52.210 & 110.454 & 3.095 & 997.331 & Yes & Yes \\
\hline Arterial roads $(\%)$ & 87 & 4.046 & 2.249 & 0 & 12.088 & No & Yes \\
\hline Local roads $(\%)$ & 87 & 92.668 & 2.667 & 79.919 & 96.508 & No & Yes \\
\hline Young population $16-25$ (\%) & 87 & 12.840 & 3.368 & 0.088 & 0.265 & No & Yes \\
\hline Unemployment rate (\%) & 10,440 & 4.641 & 1.906 & 1.200 & 18.500 & Yes & Yes \\
\hline Service employees (\%) & 87 & 63.520 & 6.278 & 44.300 & 77.500 & No & Yes \\
\hline Agriculture employees (\%) & 87 & 7.229 & 4.489 & 0.200 & 20.100 & No & Yes \\
\hline Drunkenness score & 87 & 0 & 0.778 & -2.145 & 2.007 & No & Yes \\
\hline Urban status ( urban $=1 ;$ rural $=0$ ) & 87 & 0.115 & 0.321 & 0 & 1 & No & Yes \\
\hline
\end{tabular}

over an 18-year period. Grabowski and Morrisey $(2004,2006)$ conducted their studies over an 8-year period. The respective studies of Leigh and Wilkinson (1991) and Leigh and Geraghty (2008) were each conducted over a 4 -year period. These studies found that gasoline price increases lead to a reduction in automobile traffic fatalities but an increase in motorcycle traffic fatalities.

Third, only one study has examined gasoline price effects on the occurrence of drunk-driving crashes. Still using Mississippi monthly traffic crash data from April 2004 to December 2008, Chi et al. (2011) found that increasing gasoline prices do lead to a reduction in drunk-driving crashes. Gasoline prices have greater effects on less severe crashes (e.g., property damage only crashes), whereas alcohol consumption has greater effects on more severe crashes. Overall, gasoline prices and alcohol consumption have greater effects on drunk-driving crashes than on total crashes.

Fourth, two studies (Hyatt et al., 2009; Wilson et al., 2009) have examined the association between gasoline price increases and motorcycle crashes. They found that, as gasoline prices rise, more people switch to motorcycles as the main mode of transportation. That, in turn, leads to more motorcycle injury and fatal crashes. Controlling for the number of registered motorcycles, however, motorcycle crash rates remain relatively constant (Hyatt et al., 2009). This suggests that the association between gasoline prices and motorcycle crashes are a result of the increasing number of motorcycles on the road rather than a function of driving behaviors.

Fifth, some of the studies mentioned above have also addressed the demographic variation of the effects. In general, gasoline price increases have a higher impact on younger drivers than on older drivers (Chi et al., 2010, 2012, 2013; Grabowski and Morrisey, 2004), a higher impact on female drivers than on male drivers (Chi et al., 2010, 2011), and a similar impact on white drivers and black drivers (Chi et al., 2010, 2011). While Hyatt et al. (2009) also found that the association between gasoline prices and traffic crashes differed statistically significantly by age and gender, the actual differences were found to be negligible.

Sixth, gasoline prices were also found to have both short-term (immediate) and long-term (delayed) effects. While most of the studies only examined the short-term effects of gasoline price changes on traffic crashes, four studies (Chi et al., 2010, 2012, 2013; Grabowski and Morrisey, 2004) investigated both the immediate and delayed effects. They found that the immediate effects are generally stronger than the delayed effects. In summary, existing studies have examined gasoline price effects on traffic crashes by crash types, demographic characteristics, and the endurance of effects.

\section{Data}

In this study, we examined the possibly different effects of gasoline prices on the incidence of traffic crashes in urban versus rural areas on the basis of county-level data from 1998 to 2007 in Minnesota. The data included monthly total crashes, PDO crashes, injury crashes, fatal crashes, monthly retail gasoline prices, and urban status. We also obtained data on variables that are potentially related to traffic crashes; these included vehicle miles traveled (VMT), percentages of young population, unemployment rate, road types, percentages of employees by industry, and drunkenness. The descriptive statistics of the variables are shown in Table 2.

\subsection{Total crashes, PDO crashes, injury crashes, and fatal crashes}

The crash data used in this study are vehicle-related crashes from 1998 to 2007 at the county level in Minnesota. The dataset, collected and compiled by the Minnesota Office of Traffic Safety, catalogues each crash's time, date, location, and level of severity. From this dataset, we generated the number of total crashes, PDO crashes, injury crashes, and fatal crashes for each county for every month from 1998 to 2007. The latter three types of crashes account for $68.4 \%, 31 \%$, and $0.6 \%$ of the total crashes, respectively.

\subsection{Gasoline prices}

Gasoline prices were obtained from the U.S. Department of Energy's Energy Information Administration (2010). The per-gallon prices are the average retail prices from all gasoline outlets in Minnesota. The data were collected for every month from 1998 to 2007. Gasoline prices are adjusted for inflation in January 2008 dollars.

It is possible that Minnesota drivers close to the state border might purchase gasoline from neighboring states if their gasoline prices are less expensive or vice versa. That would skew the actual gasoline prices that Minnesota drivers pay. In order to identify the potential impact of this, we obtained monthly data for gasoline prices from 1998 to 2007 in neighboring states (including North Dakota, South Dakota, Iowa, and Wisconsin) to compare those of Minnesota. We found that the monthly gasoline prices in the study period are very similar between Minnesota and its neighboring states: on average, gasoline prices in Minnesota were $1.26 \%$ (or 1 cent) higher than in neighboring states. Thus, while it is possible that Minnesota drivers on the state border might purchase gasoline from neighboring states, the impact would be negligible. Therefore, we rely on the average monthly retail prices from all gasoline outlets in Minnesota for this study.

\subsection{Urban/rural status}

There are many urban and rural classifications, but a standard does not exist (Chi, 2012). In this study, we classify our urban 


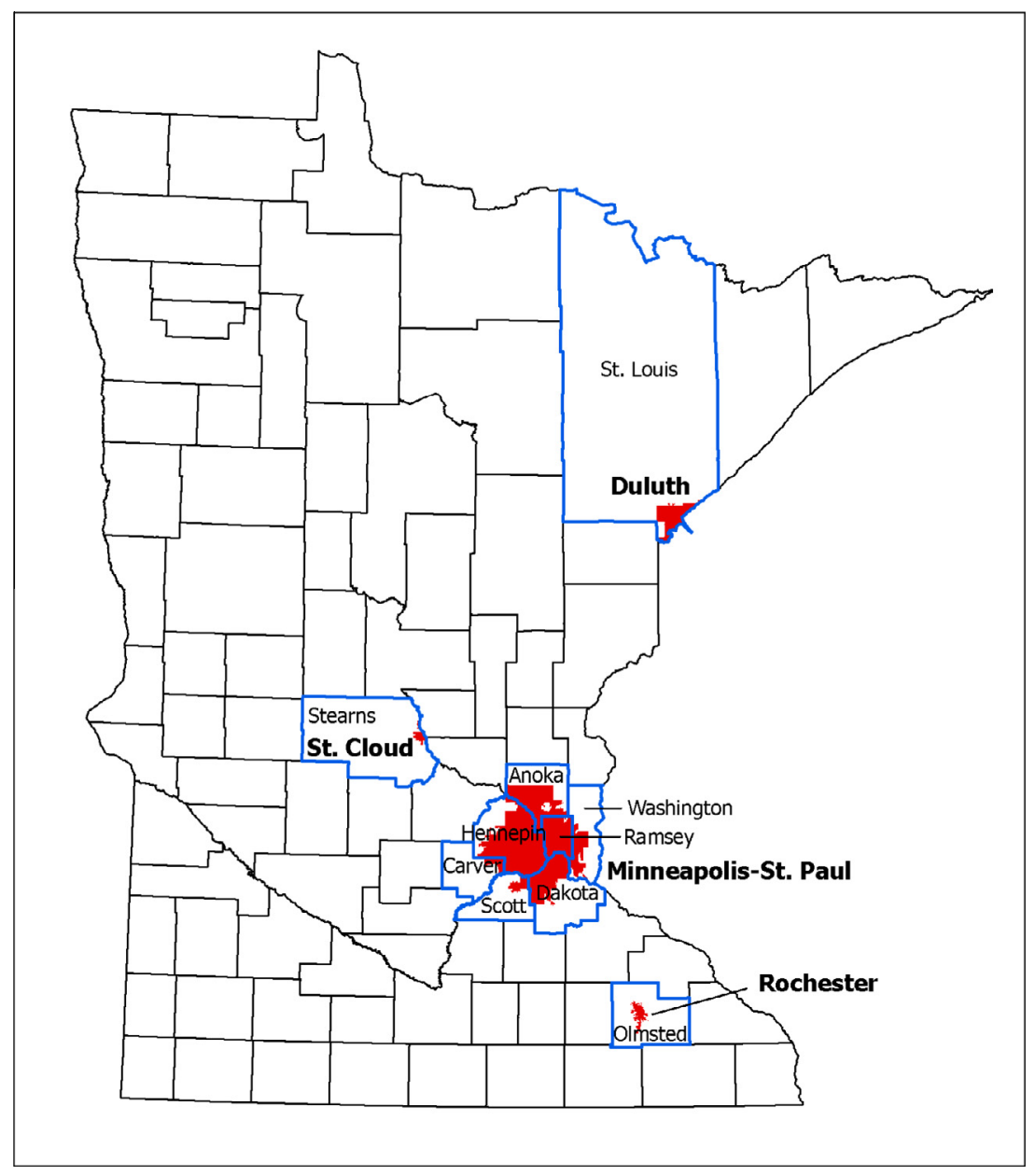

Fig. 1. Urban counties and major cities in Minnesota.

and rural counties by using a combination of the 1990 Census Urbanized Areas, as delineated by the U.S. Census Bureau, and the 2003 Metropolitan and Micropolitan Statistical Areas (MMSAs), as defined by the U.S. Office of Management and Budget. The 1990 Census Urbanized Areas are mostly principal cities, which consist of densely settled territory that contains at least 50,000 people. The counties that fall into the metropolitan statistical areas and contain urbanized areas are classified as urban counties, which include Anoka, Carver, Dakota, Hennepin, Ramsey, Scott, Washington (the seven major Twin Cities counties), Olmsted (Rochester), St. Louis (Duluth), and Stearns (St. Cloud). These counties have public transportation systems. The other 77 counties are classified as rural counties. The urban and rural status is illustrated in Fig. 1.

\subsection{Control variables}

Traffic crashes in general are affected by four categories of variables: traffic characteristics, road characteristics, socioeconomic factors, and drunk driving (Quddus, 2008). In this study, we controlled for the four categories of variables. First, VMT is an important variable to explain the variation of crashes on the road; higher VMT is always associated with more crashes (Huang and Levinson, 2010). We used VMT estimates by county and month in this study. The Minnesota Department of Transportation compiled and reported the annual VMT by county from 1998 to 2007. Based on the annual county-level VMT data and the traffic distribution over different months of year collected by the Automatic Traffic Recorder Stations (ATR) installed on the state's interstates, trunk highways, county state aid highways, and municipal state aid streets, we estimated monthly VMT at the county level. ${ }^{4}$ VMT was used as a crash exposure variable in this study; therefore, the models examined gasoline price effects on crash rates rather than on crash counts.

Second, road characteristics are found to be associated with crash occurrences (Quddus, 2008). Well-paved roads and lowdensity road networks are generally associated with fewer occurrences and lower rates of traffic crashes. Road types are used in this study to represent road characteristics. Minnesota has three types of roads: freeways, arterial roads, and local roads. Road type data were obtained from the Minnesota Department of Transportation (2010). The percentages of arterial roads and locals roads in each county were calculated and used in the analysis.

Third, four socioeconomic variables measuring young population and employment were controlled for in the analysis. The

\footnotetext{
4 To estimate the monthly VMT, we assume that the distribution of VMT by month in a year in a county is the same as the distribution of the traffic counts by month in the year in the county. Thus the ratio of traffic counts in each month to annual traffic counts is used as the ratio of VMT by month. Because some counties have ATR stations and thus have traffic data but others do not, the procedures for estimating their monthly VMTs are different. For a county that has at least one ATR station, the monthly traffic counts from the ATR stations in the county are aggregated, based on which the ratio of traffic counts in each month to annual traffic counts is computed. For a county without ATR stations, we calculate the ratio using the aggregated traffic data from the counties adjacent to it and use the monthly traffic ratio as the monthly VMT ratio. For counties whose adjacent counties do not have sufficient traffic data, we use the state-wide monthly traffic count ratio based on the traffic counts from all stations
} 
percentage of the young population (ages 16-25) was used as a control variable. Young drivers are more likely to get involved in crashes than older drivers (Chi et al., 2010). The cohort with the highest crash rate consists of younger drivers under the age of 24. Their high crash rates have been attributed to immaturity and driving inexperience, poor risk perception, excessive risktaking, poor vehicle handling skills, and comparatively high incidences of nighttime driving (e.g., Arnett, 2002; Williams, 2003; Williams et al., 1998).

Unemployment rates are used as a control variable because economic conditions affect consumers' ability to afford gasoline, which, in turn, affects the occurrence of traffic crashes (Graham and Glaister, 2003; Leigh and Wilkinson, 1991; Quddus, 2008). The unemployment rates for each county for each month from 1998 to 2007 were obtained from the Minnesota Department of Employment and Economic Development (2011). The percentages of employees working in the service industries and the agricultural industry, the two main industries in Minnesota, were also used to represent employment and socioeconomic conditions. The data were derived from the 2000 U.S. Census Bureau and are available at the county level.

Fourth, drunkenness in each county was used as a control variable. Alcohol intoxication impairs a driver's risk assessment and safe driving skills and thus increases the risk of crashes (Leigh and Wilkinson, 1991). The drunkenness measure was obtained from the County Health Rankings, a collaborative project conducted by the University of Wisconsin-Madison Population Health Institute (2011) and the Robert Wood Johnson Foundation. Their data measure excessive drinking in each county on the basis of the 2003-2009 Behavioral Risk Factor Surveillance System (BRFSS) by the Centers for Disease Control and Prevention (2011). Some researchers argue that other variables such as vehicle characteristics, travel speeds, driving behaviors, and administrative driver's suspension also affect traffic safety (Leigh and Geraghty, 2008). At the individual level such factors have some variation, yet at the aggregated county level these factors have much less variation and therefore presumably much less explanatory effect on traffic safety. As this study is conducted at the aggregated county level, these factors are not considered in this study.

The considered variables, however, do not all vary by month and county (Table 2). Only crashes, unemployment, and VMT are both time-variant and space-variant. Gasoline prices are timevariant but space-invariant. Other variables (percentage of young population, road types, percentage of employees by industry, and drunkenness) are space-variant but time-invariant. The invariance by time or by space limits the robustness of the results. The time trend was controlled for as a continuous variable, i.e., January $1998=1$, February $1998=2, \ldots$, December $2007=120 .^{5}$

\section{Methods}

The objective of this study was to develop a relationship between the incidence of traffic crashes and gasoline prices while controlling for other factors using the data related to traffic crashes in Minnesota as discussed above. Two issues needed to be considered when selecting a suitable statistical model:

1. Traffic crashes are random and non-negative count events.

2. The data are panel or longitudinal (i.e., cross-sectional and time-series).

\footnotetext{
${ }^{5}$ The time trend could be alternatively controlled by using the year 1998 as the reference category. Our test for the models, however, does not suggest a large difference in the results.
}

According to the crash modeling literature (e.g., Shankar et al., 1998; Chin and Quddus, 2003), appropriate models for panel count data are random- or fixed-effects Poisson models and random- or fixed-effects negative binomial models. These models are adequate tools on the condition that panel data should preserve stationarity (i.e., the monthly crash data are not serially correlated). Since crash data normally exhibit overdispersion (i.e., the observed variance is higher than the mean), the application of Poisson models may be inappropriate in this case (c.f., Lord and Mannering, 2010). The random- or fixed-effects over-dispersion model can be expressed as follows (Hausman et al., 1984):

$Y_{i t} \mid \gamma_{i t} \sim \operatorname{Poisson}\left(\gamma_{i t}\right)$

where $Y_{i t}$ represents the annual number of observed traffic crashes recorded in a county $i$ at month $t ; \gamma_{i t} \mid \delta_{i} \sim \operatorname{gamma}\left(\mu_{i t}, \delta_{i}\right)$ with $\mu_{i t}=$ $\exp \left(\beta_{0}+\boldsymbol{X}_{i t} \boldsymbol{\beta}+\right.$ offset $\left._{i t}\right)$ and $\delta_{i}$ is the dispersion parameter; $\boldsymbol{X}_{i t}$ stands for the vector of explanatory variables; $\boldsymbol{\beta}$ is the vector of parameters to be estimated and the offset variable controls for exposure in crash counts.

In a fixed-effects model, parameter $\delta_{i}$ is eliminated by the conditioning arguments (see Hausman et al., 1984). In a randomeffects model, $\mu_{i t}$ varies across years even if the $\boldsymbol{X}_{i t}$ 's are constant. $\delta_{i}$ is independent of $\boldsymbol{X}_{i t}$ and is randomly distributed across groups with an assumption of $\delta_{i} /\left(1+\delta_{i}\right) \sim \operatorname{Beta}(r, s)$; therefore, there is randomness both across county and across time.

On the one hand, a fixed-effects model cannot handle time-invariant variables, but it allows county-specific unobserved variables to be correlated with the regressors. On the other hand, a random-effects model can handle time-invariant variables, but there is a strong assumption that country-specific unobserved factors are uncorrelated with the regressors. Since the dataset contains several time-invariant variables (see Table 2), a randomeffects Negative Binomial (NB) model was considered preferable. However, one could have employed a Hausman (1978) test to identify the suitable model.

Since the panel data used in this study have a large number of temporal units (i.e., $T=120)$ for each of the counties $(N=87)$, the Levin-Lin-Chu (LLC) unit-root test (Levin et al., 2002) suitable for panel data was performed to see whether the monthly crashes exhibit stationarity. The null hypothesis for the test states that all the panels contain a unit root. Different specifications of the LLC test (i.e., cross-sectional correlation) were examined, and the results suggested that the monthly traffic crashes by county in Minnesota are not serially correlated. This implied that a random-effects NB model can be applied to the data.

Based on the stated hypotheses, two sets of models were estimated. In the first set of models, crash counts are a function of gasoline prices and control variables with VMT as an exposure variable. In the second set of models, crash counts are a function of gasoline prices, urban status, the interaction term of gasoline prices and urban status, and control variables with VMT as an exposure variable. Because VMT was used as an exposure variable, the models actually examined gasoline price effects on crash rates rather than on crash counts. Since the effect of gasoline prices on traffic crashes may vary by crash types, each of the two sets of models were estimated for four crash categories: total crashes, PDO crashes, injury crashes, and fatal crashes. Therefore, a total of eight models were estimated. The results are reported in the next section.

\section{Results}

\subsection{Gasoline prices and crashes}

The first step is to illustrate the relationship between gasoline prices and traffic crashes. For that purpose, Fig. 2 shows gasoline 


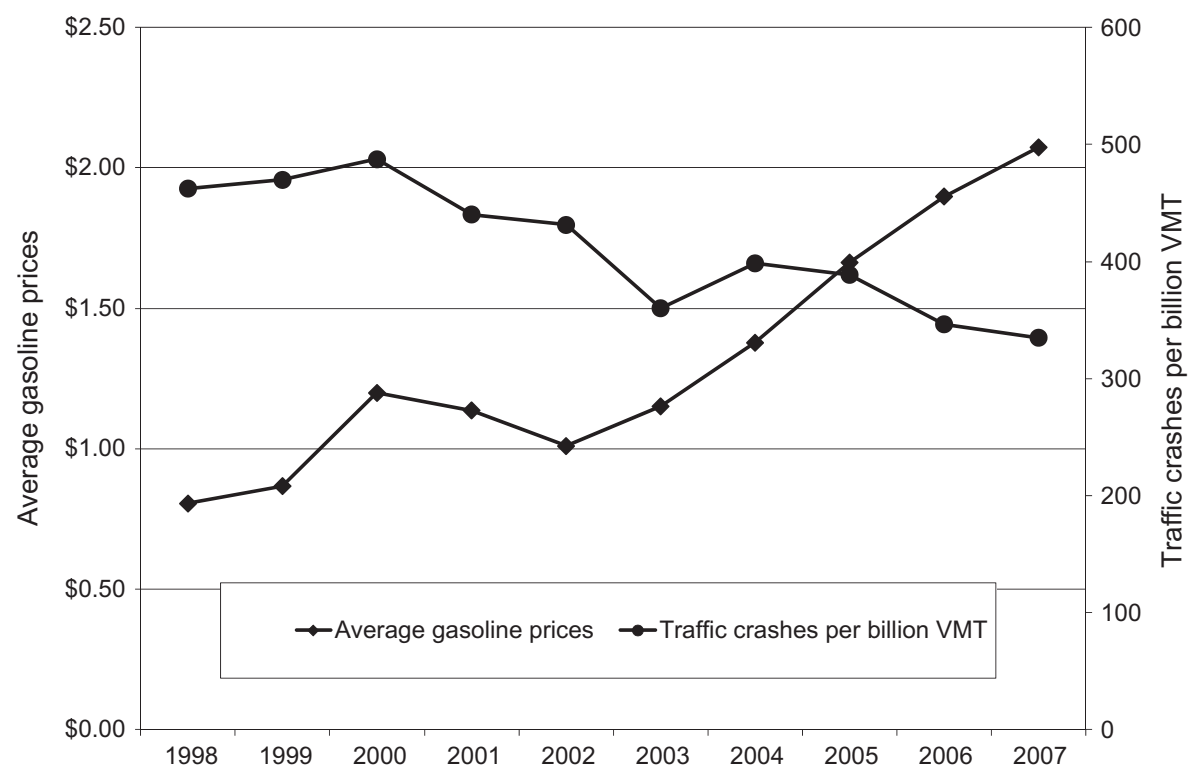

Fig. 2. Annual average gasoline prices (in January 2008 dollars) and annual total traffic crashes per billion VMT, 1998-2007, Minnesota.

prices (adjusted for inflation in January 2008 dollars) and total traffic crashes per billion VMT from 1998 to 2007 in Minnesota. The data were aggregated to the annual level in order to eliminate seasonal fluctuations. Fig. 2 approximately demonstrates a negative association between gasoline prices and traffic crashes: as gasoline prices rise, crashes per billion VMT are reduced.

The results from the random-effects negative binomial regression models support the above observation (Table 3 ). To facilitate the interpretation, we calculated the elasticities of crashes with respect to gasoline prices, when they are statistically significant at the level of $p \leqslant 0.05$ for a two-tail test (Table 5). The elasticities were calculated using the average gasoline price of $\$ 1.515$ as presented in Table 2 . For a $1 \%$ increase in gasoline prices, the expected total traffic crashes per million VMT decreases by $0.35 \%$, holding all other variables constant. Total crashes per million VMT are also affected by other variables. The drunkenness score and the percentage of service employees are negatively associated with total crashes per million VMT. The percentages of arterial roads and local roads, unemployment rate, and the percentage of agricultural employees are associated positively with total crashes per million VMT.

According to the results, gasoline prices also have statistically significant effects on PDO, injury, and fatal crashes. A $1 \%$ increase in gasoline prices is associated with a $0.45 \%$ decrease in PDO crashes per million VMT, a $0.15 \%$ decrease in injury crashes per million VMT, and a $0.22 \%$ decrease in fatal crashes per million VMT, holding all other variables constant (Table 4). This result is consistent with that obtained by Chi et al. (2011), who found that gasoline prices have stronger effects on reducing less severe crashes.

\subsection{Difference of the effects between urban and rural counties}

We further examined the possible variations of gasoline price effects on crashes between urban and rural counties. For each one of Models $1,2,3$, and 4, we added a dummy variable indicating urban status ( $1=$ urban; $0=$ rural) and an interaction variable between gasoline prices and urban status (Table 4). The models that control for the urban and rural difference are Models 5, 6, 7, and 8. These models are better fitted to data than their corresponding models in Table 3 as indicated by the log likelihood at convergence.
The elasticities of crashes per million VMT with respect to gasoline prices (when statistically significant at the level of $p \leqslant 0.05$ for a two-tail test) are shown in Table 5 . Higher gasoline prices are associated with fewer total traffic crashes per million VMT in both rural and urban areas (Table 4 ). For a $1 \%$ increase in gasoline prices, the expected total crashes per million VMT in rural areas decrease by $0.41 \%$, holding all other variables constant; the expected total crashes per million VMT in urban areas decrease by $0.28 \%$, holding all other variables constant.

Higher gasoline prices also reduce PDO crashes, injury crashes, and fatal crashes in both rural and urban areas (Table 5). In rural areas, for a $1 \%$ increase in gasoline prices, PDO crashes per million VMT decrease by $0.52 \%$, injury crashes per million VMT decrease by $0.20 \%$, and fatal crashes per million VMT decrease by $0.23 \%$, holding all other variables constant. In urban areas, for a $1 \%$ increase in gasoline prices, PDO crashes per million VMT decrease by $0.36 \%$, injury crashes per million VMT decrease by $0.11 \%$, and fatal crashes per million VMT decrease by $0.22 \%$, holding all other variables constant.

$T$-tests ${ }^{6}$ were used to examine whether the estimated elasticities are statistically different between rural and urban areas for each of the four crash types. The results indicate that the differences are statistically significant (at a $p \leqslant 0.05$ level) for total crashes per million VMT, PDO crashes per million VMT, and injury crashes per million VMT; gasoline prices have stronger effects on reducing rural crash rates than urban crash rates (Table 5). A $1 \%$ increase in gasoline prices is associated with $0.13 \%$ more reduction in rural crashes per million VMT than urban crashes per million VMT (with a range of $0.14 \%$ to $0.12 \%$ at a $95 \%$ confidence interval). A $1 \%$ increase in gasoline prices is also associated with $0.16 \%$ more reduction in PDO crashes per million VMT in rural areas than in urban areas (with a range of $0.17 \%$ to $0.15 \%$ at a $95 \%$ confidence interval), and $0.09 \%$ more reduction in injury crashes per million VMT in rural areas than in urban areas (with a range of $0.10 \%$ to $0.09 \%$ at a $95 \%$ confidence interval). The difference of elasticities of fatal crashes per million VMT between rural and urban areas, however, is not statistically significant.

\footnotetext{
${ }^{6}$ The elasticities used for $t$-tests were estimated at the observed data points. Since the data sample $(=10,440)$ is large, we assume that the estimated elasticities follow a normal distribution approximately so that the $t$-tests can be used for testing the
} difference of elasticities between rural and urban areas. 
Table 3

Results of random-effects negative binomial regression models without the interaction term between gasoline prices and urban status, 1998-2007, Minnesota.

\begin{tabular}{|c|c|c|c|c|c|c|c|c|}
\hline \multirow[t]{2}{*}{ Variables } & \multicolumn{2}{|c|}{ Model 1 (total crashes) } & \multicolumn{2}{|c|}{ Model 2 (PDO crashes) } & \multicolumn{2}{|c|}{ Model 3 (injury crashes) } & \multicolumn{2}{|c|}{ Model 4 (fatal crashes) } \\
\hline & Coef. & $t$-Score & Coef. & $t$-Score & Coef. & $t$-Score & Coef. & $t$-Score \\
\hline Gasoline prices & -0.2338 & -17.74 & -0.2999 & -18.71 & -0.1012 & -7.77 & -0.1448 & -2.46 \\
\hline Arterial roads (\%) & 0.1000 & 7.50 & 0.1224 & 9.26 & 0.1496 & 6.76 & 0.0609 & 2.75 \\
\hline Local roads $(\%)$ & 0.0414 & 3.28 & 0.0457 & 3.43 & 0.0575 & 2.35 & 0.0061 & 0.32 \\
\hline Young population $16-25$ (\%) & -0.0010 & -0.17 & 0.0014 & 0.23 & 0.0375 & 3.46 & -0.0118 & -1.05 \\
\hline Unemployment rate (\%) & 0.0207 & 7.57 & 0.0366 & 11.23 & -0.0117 & -3.83 & -0.0160 & -1.28 \\
\hline Service employees (\%) & -0.0331 & -9.36 & -0.0403 & -11.39 & -0.0589 & -8.55 & -0.0053 & -0.85 \\
\hline Agriculture employees (\%) & 0.1202 & 19.74 & 0.1091 & 18.22 & 0.0770 & 6.35 & 0.0165 & 1.75 \\
\hline Drunkenness score & -0.0576 & -2.06 & -0.0669 & -2.38 & -0.0989 & -1.99 & 0.0213 & 0.47 \\
\hline Time trend & -0.0006 & -3.15 & $8.72 \mathrm{E}-6$ & 0.04 & -0.0020 & -9.70 & -0.0012 & -1.36 \\
\hline Million VMT (exposure) & 1.0000 & - & 1.0000 & - & 1.0000 & - & 1.0000 & - \\
\hline Constant & -3.5282 & -2.85 & -0.8989 & -2.99 & -3.0498 & -1.27 & 1.0989 & 0.29 \\
\hline Parameter: $r$ & 1.8983 & 6.86 & 1.8555 & 6.8867 & 4.5247 & 5.91 & 3431.1960 & 0.31 \\
\hline Parameter: $s$ & 4.2302 & 6.23 & 3.9900 & 6.2508 & 2.2857 & 5.72 & 14.2115 & 4.88 \\
\hline Log-likelihood at convergence & \multirow{2}{*}{\multicolumn{2}{|c|}{$\begin{array}{l}-40,082.71 \\
N=87, T=120\end{array}$}} & \multirow{2}{*}{\multicolumn{2}{|c|}{$\begin{array}{l}-37,560.81 \\
N=87, T=120\end{array}$}} & \multirow{2}{*}{\multicolumn{2}{|c|}{$\begin{array}{l}-29,199.19 \\
N=87, T=120\end{array}$}} & \multirow{2}{*}{\multicolumn{2}{|c|}{$\begin{array}{l}-8358.3 \\
N=87, T=120\end{array}$}} \\
\hline Number of observations & & & & & & & & \\
\hline
\end{tabular}

Table 4

Results of random-effects negative binomial regression models with the interaction term between gasoline prices and urban status, 1998-2007, Minnesota.

\begin{tabular}{|c|c|c|c|c|c|c|c|c|}
\hline \multirow[t]{2}{*}{ Variables } & \multicolumn{2}{|c|}{ Model 5 (total crashes) } & \multicolumn{2}{|c|}{ Model 6 (PDO crashes) } & \multicolumn{2}{|c|}{ Model 7 (injury crashes) } & \multicolumn{2}{|c|}{ Model 8 (fatal crashes) } \\
\hline & Coef. & $t$-Score & Coef. & $t$-Score & Coef. & $t$-Score & Coef. & $t$-Score \\
\hline Gasoline prices & -0.3306 & -20.41 & -0.3437 & -20.19 & -0.1322 & -9.22 & -0.1535 & -2.41 \\
\hline Urban status ( urban $=1 ;$ rural $=0$ ) & -1.2264 & -18.36 & -1.2688 & -18.57 & -0.8071 & -7.70 & -0.4333 & -3.13 \\
\hline Gasoline prices X Urban status & 0.1273 & 9.42 & 0.1064 & 5.82 & 0.0607 & 4.87 & 0.0092 & 0.16 \\
\hline Arterial roads $(\%)$ & 0.0158 & 1.06 & 0.0633 & 4.87 & 0.0947 & 3.97 & 0.0434 & 2.08 \\
\hline Local roads $(\%)$ & 0.0137 & 0.86 & 0.0231 & 1.86 & 0.0212 & 0.90 & -0.0064 & -0.35 \\
\hline Young population $16-25$ (\%) & -0.0110 & -1.57 & -0.0153 & -2.51 & 0.0172 & 1.59 & -0.0183 & -1.75 \\
\hline Unemployment rate (\%) & -0.0209 & -8.11 & 0.0366 & 11.30 & -0.0129 & -4.20 & -0.0189 & -1.52 \\
\hline Service employees (\%) & 0.0072 & 1.58 & -0.0050 & -1.30 & -0.0343 & -4.60 & 0.0020 & 0.33 \\
\hline Agriculture employees (\%) & -0.0308 & -4.08 & 0.0778 & 12.86 & 0.0430 & 3.57 & 0.0068 & 0.75 \\
\hline Drunkenness score & 0.0698 & 2.29 & -0.0687 & -2.50 & -0.0711 & -1.40 & 0.0282 & 0.67 \\
\hline Time trend & -0.0006 & -2.79 & $8.59 \mathrm{E}-5$ & 0.35 & -0.0019 & -9.30 & -0.0011 & -1.25 \\
\hline Million VMT (exposure) & 1.0000 & - & 1.0000 & - & 1.0000 & - & 1.0000 & - \\
\hline Constant & -2.2876 & -1.95 & -3.1861 & -2.62 & -0.4437 & -0.19 & 2.5131 & 0.47 \\
\hline Parameter: $r$ & 2.1343 & 6.82 & 2.1036 & 6.85 & 5.4130 & 5.85 & 6671.3560 & 0.20 \\
\hline Parameter: $s$ & 4.8808 & 6.25 & 4.6243 & 6.29 & 2.7926 & 5.64 & 17.9196 & 4.55 \\
\hline Log-likelihood at convergence & $-39,903.03$ & & $-37,375.03$ & & $-29,164.24$ & & -8351.57 & \\
\hline Number of observations & $N=87, T=120$ & & $N=87, T=120$ & & $N=87, T=120$ & & $N=87, T=120$ & \\
\hline
\end{tabular}

Table 5

Elasticities of crashes per million VMT with respect to gasoline prices, 1998-2007, Minnesota.

\begin{tabular}{|c|c|c|c|c|}
\hline Elasticities & Total crashes & PDO crashes & Injury crashes & Fatal crashes \\
\hline Overall & -0.354 & -0.454 & -0.153 & -0.219 \\
\hline Rural areas & -0.411 & -0.521 & -0.200 & -0.233 \\
\hline Urban areas & -0.279 & -0.360 & -0.108 & -0.219 \\
\hline Difference between rural and urban areas (95\% confidence interval) & $\begin{array}{l}-0.132 \\
(-0.140,-0.124)\end{array}$ & $\begin{array}{l}-0.161 \\
(-0.171,-0.151)\end{array}$ & $\begin{array}{l}-0.092 \\
(-0.096,-0.088)\end{array}$ & \\
\hline
\end{tabular}

Notes. Overall elasticities of crashes per million VMT were calculated using gasoline price coefficients estimated in Table 3 and the average gasoline prices of $\$ 1.515$.

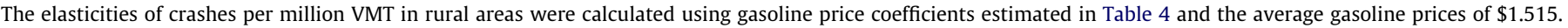

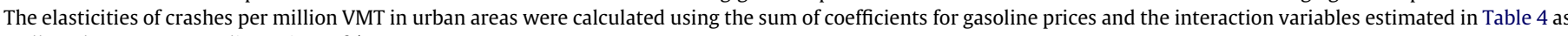
well as the average gasoline prices of $\$ 1.515$.

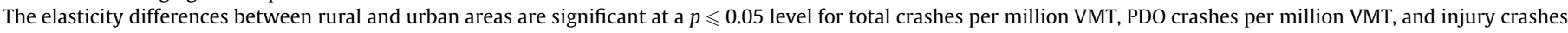
per million VMT, but not for fatal crashes per million VMT.

\section{Summary and discussion}

An increasing body of literature examines the role of gasoline prices in the occurrence of traffic crashes. Nevertheless, no studies have investigated the possibly different effects in urban versus rural areas. In this study, we used traffic crash data from 1998 to 2007 in Minnesota to investigate the possible difference of gasoline price effects on traffic crashes per million VMT in urban versus rural areas. The results indicate a significant difference of gasoline price effects on total crashes in urban versus rural areas. The effects of gasoline prices are stronger in rural than in urban areas: for a $10 \%$ increase in gasoline prices, total crashes decrease $4.1 \%$ in rural areas and $2.8 \%$ in urban areas. Gasoline prices also have significant effects in reducing PDO crashes and injury crashes in both urban and rural areas; the effects are statistically stronger in rural areas than in urban areas. For a $10 \%$ increase in gasoline prices, PDO crashes decrease $5.2 \%$ in rural areas and $3.6 \%$ in urban areas; injury crashes decrease by $2 \%$ in rural areas and $1.1 \%$ in urban areas. Gasoline prices also have significant effects in reducing fatal crashes in urban and rural areas; however, the difference is not significant. 
For a $10 \%$ increase in gasoline prices, fatal crashes decrease $2.3 \%$ in rural areas and $2.2 \%$ in urban areas. The finding is consistent with the one from the Chi et al. (2011) study, which found gasoline price effects to be stronger on less severe crashes but little effects on more severe crashes. In addition, our findings indicate that gasoline price effects are stronger in rural areas than in urban areas for total crashes, PDO crashes, and injury crashes, but not for fatal crashes. This study contributes to the literature by understanding the difference of gasoline price effects on crashes in urban versus rural areas.

We initially had two competing explanations. On the one hand, we hypothesized that gasoline price effects on reducing crashes are stronger in urban areas than in rural areas as urban commuters could switch from personal vehicles to public transportation for work-related trips, or even non-work related trips, in response to higher gasoline prices. On the other hand, we hypothesized gasoline price effects are stronger in rural areas than in urban areas as gasoline is one type of consumer goods and the relatively lower level of income makes rural commuters more vulnerable to gasoline price increases. Our findings seem to support the second explanation. Income seems to be a stronger factor than alternative transportation models in explaining the difference of gasoline price effects on crashes between urban and rural areas. In the study period, the median household income was $\$ 67,670$ in urban areas and $\$ 46,708$ in rural areas. ${ }^{7}$ That represents $45 \%$ higher median household income in urban areas than in rural areas. Rural commuters have much less disposable income than urban commuters and rural commuters are more vulnerable to gasoline price increases; therefore, identical or similar gasoline price increases would affect traffic safety in rural areas more than in urban areas. Nevertheless, this was not statistically tested in the study. In future research, we would like to test if the urban-rural difference of gasoline price effects is due to the modes of transportation or income levels.

The findings suggest that higher gasoline prices lead to fewer traffic crashes; the effects are stronger in rural than in urban areas. But how does that translate into the actual number of traffic crashes? More specifically, how many crashes would not have occurred or how many more crashes would have occurred if gasoline prices had kept at an assumed level? How does that differ between rural and urban areas? In order to answer these practical and policy-relevant questions, we used the estimated elasticities from the findings to predict the number of crashes at assumed levels of gasoline prices (Table 6). If gasoline prices had remained constant at the 1998 level of $\$ 0.93$ from 1998 to 2007, applying the estimated elasticities would result in a predicted increase in total crashes of 173,907 with 72,098 in rural areas and 101,809 in urban areas. Those represent an increase of $19 \%$ from the actual number of crashes, $25 \%$ increase in rural areas, and $17 \%$ increase in urban areas. If gasoline prices had been at the summer 2008 level of $\$ 4$ from 1998 to 2007, applying the estimated elasticities would result in a predicted decrease in total crashes of 180,870 with 75,923 in rural areas and 104,947 in urban areas. Those represent a decrease of $20 \%$ from the actual number of crashes, $26 \%$ decrease in rural areas, and $17 \%$ decrease in urban areas. The findings suggest that if policy makers wish to reduce traffic crashes, increasing gasoline taxes might be an option. However, doing so would increase travel costs for commuters using personal vehicles. This would complicate equity concerns as gasoline tax increases would be a bigger burden for low-income and even middle-class drivers than highincome drivers. Therefore, if gasoline tax increases become a

\footnotetext{
7 The data were obtained from the U.S. Census Bureau, which estimated the median household income on the basis of the American Community Survey and the Current Population Survey data. The data are available at http://www.census.gov/did/www/ saipe/county.html.
}

Table 6

Actual and predicted traffic crashes assuming gasoline prices at the 1998 level and the summer 2008 level, 1998-2007, Minnesota.

\begin{tabular}{|c|c|c|c|}
\hline & $\begin{array}{l}\text { Total } \\
\text { crashes }\end{array}$ & $\begin{array}{l}\text { Rural } \\
\text { crashes }\end{array}$ & $\begin{array}{l}\text { Urban } \\
\text { crashes }\end{array}$ \\
\hline Actual crashes & 893,668 & 293,414 & 600,254 \\
\hline $\begin{array}{l}\text { Predicted crashes at the } 1998 \text { level } \\
\quad(\$ 0.93)\end{array}$ & $1,067,575$ & 365,512 & 702,063 \\
\hline Percent increase & 19.46 & 24.57 & 16.96 \\
\hline $\begin{array}{l}\text { Predicted crashes at the summer } 2008 \\
\text { level }(\$ 4)\end{array}$ & 712,798 & 217,491 & 495,307 \\
\hline Percent decrease & 20.24 & 25.88 & 17.48 \\
\hline
\end{tabular}

consideration, it is important to invest mass transit systems so that vulnerable drivers could switch to public transportation (Chi et al., 2012).

It should be noted that our estimated elasticity of crashes with respect to gasoline prices, which is -0.35 , seems much higher than elasticities of demand with respect to gasoline prices estimated in previous studies. For example, it was found that the elasticity of demand with respect to gasoline prices was -0.12 in a metaanalysis study conducted by Brons et al. (2008). There are three possible reasons for the big difference. First, although the two estimated elasticities are related, they measure different things: our estimate is for crashes per million VMT (which is a rate) with respect to gasoline prices, but the Brons et al. (2008) study was aimed to determine demand (which is a count or frequency) with respect to gasoline prices. Second, the effects that gasoline prices have on reducing crashes are much stronger on young drivers than on older drivers (Chi et al., 2010; Grabowski and Morrisey, 2004); for the identical gasoline price increase, the total reduction in crashes and crash rates would be higher than the total reduction in demand. Third, the high elasticity estimate of crashes per VMT with respect to gasoline price increases may be due to a data limitation. Our dataset is composed of 10,440 unique observations of crashes but only 120 unique observations of gasoline prices, which reduces the robustness of the models.

That said, we feel that our results are relatively reasonable compared to the studies that specifically focus on elasticities of crash rates with respect to gasoline prices. For example, the elasticity is found to be -0.23 for fatal crashes per capita with respect to gasoline prices over a 2-year period (Grabowski and Morrisey, 2004), -0.25 for total crashes per million VMT with respect to current gasoline prices and -0.47 for total crashes per million VMT with respect to gasoline prices with a 1-year lag (Chi et al., 2010).

This study might benefit from further analysis in three methodological directions. First, 2-stage least squares (2SLS) models might improve model estimates as injury and fatal crash counts are likely endogenous with VMT but are not with gasoline prices. The 2SLS models could include two parts-the reduced function to predict VMT and the structural function to predict crash counts (Huang and Levinson, 2010). Second, the correlation among PDO, injury, and fatal crashes could be controlled for and might be better modeled in one single model as gasoline price effects vary by the severity of crashes. Third, future research could benefit from Bayesian spatial analysis by including neighboring states. Our data covered the 87 counties of Minnesota; it is possible that Minnesota drivers, especially those close to the state border, purchase gasoline from neighboring states and drivers from neighboring states purchase gasoline from Minnesota. Also, crashes might show spatial correlation, and gasoline price effects might show spatial variations. Models incorporating neighboring states and spatial dependence and/or heterogeneity might provide further insights into the spatial variation of gasoline price effects on crashes. 


\section{References}

Arnett, J.J., 2002. Developmental sources of crash risk in young drivers. Injury Prevention 8 (Suppl. II), 17-23.

Brons, M., Nijkamp, P., Pels, E., Rietveld, P., 2008. A meta-analysis of the price elasticity of gasoline demand. A SUR approach. Energy Economics 30, 21052122.

Centers for Disease Control and Prevention, 2011. Behavioral Risk Factor Surveillance System. <http://www.cdc.gov/brfss/> (retrieved 11.07.11).

Chi, G., 2012. The impacts of transport accessibility on population change across rural, suburban, and urban areas: a case study of Wisconsin at subcounty levels. Urban Studies 49 (12), 2711-2731.

Chi, G., Cosby, A.G., Quddus, M.A., Gilbert, P.A., Levinson, D., 2010. Gasoline prices and traffic safety in Mississippi. Journal of Safety Research 41 (6), 493-500.

Chi, G., Zhou, X., McClure, T.E., Gilbert, P.A., Cosby, A.G., Zhang, L., Robertson, A.A., Levinson, D., 2011. Gasoline prices and their relationship to drunk-driving crashes. Accident Analysis and Prevention 43 (1), 194-203.

Chi, G., McClure, T.E., Brown, D.B., 2012. Gasoline prices and traffic crashes in Alabama, 1999-2009. Traffic Injury Prevention 13 (5), 476-484.

Chi, G., Porter, J.R., Cosby, A.G., Levinson, D., 2013. The impact of gasoline price changes on traffic safety: a time geography explanation. Journal of Transport Geography 28 (1), 1-11.

Chin, H.C., Quddus, M.A., 2003. Applying the random effect negative binomial model to examine traffic accident occurrence at signalized intersections. Accident Analysis and Prevention 35 (2), 253-259.

Currie, G., Phung, J., 2008. Understanding links between transit ridership and gasoline prices: evidence from the United States and Australia. Transportation Research Record 2063, 133-142.

Goodwin, P., Dargay, J., Hanly, M., 2004. Elasticities of road traffic and fuel consumption with respect to price and income: a review. Transport Reviews 24 (3), 275-292.

Grabowski, D.C., Morrisey, M.A., 2004. Gasoline prices and motor vehicle fatalities. Journal of Policy Analysis and Management 23 (3), 575-593.

Grabowski, D.C., Morrisey, M.A., 2006. Do higher gasoline taxes save lives? Economics Letters 90 (1), 51-55.

Graham, D.J., Glaister, S., 2003. Spatial variation in road pedestrian casualties: the role of urban scale, density and land-use mix. Urban Studies 40 (8), 1591-1607.

Hausman, J.A., 1978. Specification tests in econometrics. Econometrica 46 (6), 1251-1271.

Hausman, J.A., Hall, B.H., Griliches, Z., 1984. Econometric models for count data with an application to the Patents-R\&D relationship. Econometrica 52 (4), 909-938.

Huang, A., Levinson, D., 2010. The effects of daylight saving time on vehicle crashes in Minnesota. Journal of Safety Research 47, 513-520.

Hyatt, E., Griffin, R., Rue III, L.W., McGwin Jr., G., 2009. The association between price of regular-grade gasoline and injury and mortality rates among occupants involved in motorcycle- and automobile-related motor vehicle collisions. Accident Analysis and Prevention 41, 1075-1079.

Kopits, E., Cropper, M., 2005. Traffic fatalities and economic growth. Accident Analysis and Prevention 37, 169-178.
Leigh, J.P., Geraghty, E.M., 2008. High gasoline prices and mortality from motor vehicle crashes and air pollution. Journal of Occupational and Environmental Medicine 50 (3), 249-254.

Leigh, J.P., Wilkinson, J.T., 1991. The effect of gasoline taxes on highway fatalities. Journal of Policy Analysis and Management 10 (3), 474-481.

Levin, A., Lin, C.F., Chu, C.S.J., 2002. Unit root tests in panel data: asymptotic and finite-sample properties. Journal of Econometrics 108, 1-24.

Levinson, D., Wu, Y., 2005. The rational locator reexamined: are travel times still stable? Transportation 32, 187-202.

Lord, D., Mannering, F., 2010. The statistical analysis of crash-frequency data: a review and assessment of methodological alternatives. Transportation Research Part A: Policy and Practice 44, 291-305.

Minnesota Department of Employment and Economic Development, 2011 Minnesota Unemployment Statistics. <http://www.positivelyminnesota.com/ apps/lmi/laus/detail.aspx?geog=2704000001\&adjust=0\&graph=1> (retrieved 01.07.11).

Minnesota Department of Transportation, 2010. VMT Qualifications and Notes. <http://www.dot.state.mn.us/roadway/data/reports/vmt.html> (retrieved 10 07.11).

Quddus, M.A., 2008. Modelling area-wide count outcomes with spatial correlation and heterogeneity: an analysis of London crash data. Accident Analysis and Prevention 40 (4), 1486-1497.

Scuffham, P.A., 2003. Economic factors and traffic crashes in New Zealand. Applied Economics 35, 179-188.

Shankar, V., Albin, R., Milton, J., Mannering, F., 1998. Evaluating median crossover likelihoods with clustered accident counts: an empirical inquiry using the random effects negative binomial model. Transportation Research Record: Journal of the Transportation Research Board 1635 (1), 44-48.

Sivak, M., Schoettle, B., 2010. Toward understanding the recent large reductions in U.S. road fatalities. Traffic Injury Prevention 11, 561-566.

Traynor, T.L., 2008. Regional economic conditions and crash fatality rates-a crosscounty analysis. Journal of Safety Research 39, 33-39.

Traynor, T.L., 2009. The relationship between regional economic conditions and the severity of traffic crashes. Traffic Injury Prevention 10, 368-374.

U.S. Energy Information Administration, 2010. Minnesota Total Gasoline through Company Outlets Price by All Sellers. <http://www.eia.gov/dnav/pet/hist LeafHandler.ashx?n=PET\&s=EMA_EPM0_PTC_SMN_DPG\&f=M> (retrieved 06. 07.11).

University of Wisconsin Population Health Institute, 2011. Community Health Rankings. <http://www.countyhealthrankings.org/health-factors/alcohol-use> (retrieved 16.07.11).

Williams, A.F., 2003. Teenage drivers: patterns of risk. Journal of Safety Research 34 5-15.

Williams, A.F., Preusser, D.F., Ferguson, S.A., 1998. Fatal crashes involving 16-year old drivers: narrative descriptions. Journal of Traffic Medicine 26, 11-17.

Wilson, F.A., Stimpson, J.P., Hilsenrath, P.E., 2009. Gasoline prices and their relationship to rising motorcycle fatalities, 1990-2007. American Journal of Public Health 99 (10), 1753-1758. 